Goldschmidt 2021 Abstract

https://doi.org/10.7185/gold2021.8091

\section{Formation of hydrocarbons favors high pressure at subduction zones conditions: a study from in-situ experiments}

\author{
JINGYI HUANG ${ }^{1}$, ISABELLE DANIEL ${ }^{2}$, DIMITRI \\ SVERJENSKY ${ }^{1}$, HERVÉ CARDON ${ }^{3}$ AND GILLES \\ MONTAGNAC 4
}

${ }^{1}$ Johns Hopkins University

${ }^{2}$ Laboratoire de géologie de Lyon UMR 5276, Université Lyon1

- Ens de Lyon - CNRS

${ }^{3}$ Laboratoire de géologie de Lyon UMR 5276, ENS et Université Lyon 1

${ }^{4}$ Ecole Normale Supérieure de Lyon

Presenting Author: jyhuang@jhu.edu

Subduction zones are geological settings which could be channels for carbon transport to the deep Earth. Inorganic and organic carbon in fluids released from the subducted slab are important in water-rock interactions. Field observations of CH4$\mathrm{H} 2$ fluid inclusions in the ophicarbonates in metamorphosed ultramafic rocks have shown the possible metastability of hydrocarbon fluids at upper mantle conditions[1]. In experiments, synthesized fluids of $\mathrm{CH} 4-\mathrm{C} 2 \mathrm{H} 6-\mathrm{H} 2$ are trapped in quartz from Na-formate solution at $600-700^{\circ} \mathrm{C}$ and $1.5-2.5$ $\mathrm{GPa}[2]$. These studies suggest that pressure might be an important factor in the formation of hydrocarbons under the upper mantle conditions.

We focused on the role of pressure influencing the formation of hydrocarbons using diamond anvil cell experiments starting with $1.0 \mathrm{M} \mathrm{Ca}$-acetate solutions over a wide range of pressures $(1.5-4.6 \mathrm{GPa})$ at temperatures of 300 and $350^{\circ} \mathrm{C}$. Droplets of immiscible hydrocarbon fluid coexisting with aqueous carbonate or bicarbonate and crystals of calcite or aragonite were formed at peak pressure and temperature conditions in the experiments. Greater quantities of hydrocarbons formed at higher pressure as revealed by measuring the in situ volume percent of the droplets. Also, analysis of the Raman spectra of the aqueous solutions indicated that the reactions forming hydrocarbons were accelerated by high pressure.

In previous experiments starting with Na-acetate solutions[3], immiscible hydrocarbon droplets containing mainly methane and isobutane formed at $300{ }^{\circ} \mathrm{C}$ and $3.0 \mathrm{GPa}$. Compared to the previous Na-acetate experiments, this study found hydrocarbons that were more isobutane and propane-rich, but methane poor. In experiments at around $350{ }^{\circ} \mathrm{C}$, aromatic hydrocarbons formed which caused strong fluorescence using a $532 \mathrm{~nm}$ laser. Increase of temperature is the main reason for forming aromatic hydrocarbons in our experiments. The dried aromatic hydrocarbons were measured using a UV laser, and show peaks of bitumen.

Progress in our experiments shows that the formation of hydrocarbons is closely related to higher pressures at the same temperature. Our study supports the possible co-occurrence of hydrocarbons and carbonate minerals in subduction zones.
[1] Brovarone et al.(2017), Nature Communications 8, $1-13$.

[2] Li et al.(2017), Geochemical Perspectives Letters 3, 12-21.

[3] Huang et al.(2017), Nature Communications 8, 1-8. 